Performance of moth larvae on birch in relation to altitude, climate, host quality and parasitoids

Virtanen, $\mathrm{T}$.

Springer

1999

Virtanen, T. and Neuvonen, S. 1999. Performance of moth larvae on birch in relation to altitude, climate, host quality and parasitoids.Oecologia 120: 92-101

http://hdl.handle.net/1975/278

Downloaded from Helda, University of Helsinki institutional repository.

This is an electronic reprint of the original article.

This reprint may differ from the original in pagination and typographic detail.

Please cite the original version. 
Tarmo Virtanen · Seppo Neuvonen

\section{Performance of moth larvae on birch in relation to altitude, climate, host quality and parasitoids}

Received: 4 January 1999 / Accepted: 22 March 1999

\begin{abstract}
We studied topographical and year-to-year variation in the performance (pupal weights, survival) and larval parasitism of Epirrita autumnata larvae feeding on mountain birch in northernmost Finland in 1993-1996. We found differences in both food plant quality and parasitism between sites ranging from $80 \mathrm{~m}$ to $320 \mathrm{~m}$ above sea level. Variation in food plant quality had particularly marked effects on larval survival. The advanced phenology of the birches in relation to the start of the larval period reduced pupal weights. Parasitism rates were different between years and between sites. The clearest site differences were in the proportions of different parasitoid species: Eulophus larvarum was most abundant at the lowest-altitude sites, and Cotesia jucunda at the highest. Differences in the performance of E. autumnata were related to temperature conditions: at higher temperatures, survival and the egg production index were lower, and larval parasitism was higher than at lower temperatures. The higher parasitism at higher temperatures was probably due to greater parasitoid activity during warmer days. In the comparison of different sources of spatial and annual variation in the performance of E. autumnata, the most important factor appeared to be egg mortality related to minimum winter temperature, followed by parasitism and, finally, the variation in food plant quality. If, as predicted, the cli-
\end{abstract}

T. Virtanen $(\bowtie)^{1}$

Section of Ecology, Department of Biology,

University of Turku,

FIN-20014 Turku, Finland

e-mail: tarmo.virtanen@metla.fi, Fax: +358-16-3364640

S. Neuvonen

Kevo Subarctic Research Institute,

University of Turku,

FIN-20014 Turku, Finland

Present address:

${ }^{1}$ Finnish Forest Research Institute,

Rovaniemi Research Station, Box 16,

FIN-96301 Rovaniemi, Finland mate gradually warms up, the effects of warmer summers on the outbreaks of E. autumnata suggest a decrease in outbreak intensity.

Key words Epirrita autumnata $\cdot$ Lepidoptera: Geometridae $\cdot$ Betula pubescens ssp. czrepanovii $\cdot$ Insect outbreaks $\cdot$ Climate change

\section{Introduction}

It is generally accepted that the population dynamics of insect species showing regular cycles are driven by delayed negative feedbacks (Berryman et al. 1987; Berryman 1996). Factors causing this kind of feedback are biotic: predators, parasitoids, pathogens, or induced changes in food quality. However, even in the case of these cyclically fluctuating species, abiotic factors may synchronise outbreaks over large areas (Myers 1998) and/or determine the spatial distribution of forest damage (Tenow 1975; Martinat 1987). There is often large landscape-scale variation in insect densities during an outbreak (Kallio and Lehtonen 1973; Tenow 1975; Larsson and Tenow 1984; Broekhuizen et al. 1993; Ruohomäki et al. 1997). In addition to abiotic factors, biotic factors can also contribute to this variation. To better understand the population dynamics of insects, both the direct effects of climate and those mediated via biotic factors (host quality, natural enemies) should be incorporated in spatially explicit population dynamic models (cf. Hunter 1997; see also Lawton 1994).

Epirrita autumnata (Bkh.) is a geometrid moth periodically defoliating large areas of mountain birch (Betula pubescens ssp. czerepanovii) forest, sometimes causing the widespread death of trees along the Scandinavian mountain chain and in Northern Fennoscandia (Tenow 1972; Kallio and Lehtonen 1973). E. autumnata shows regular cycles with variable amplitude in some parts of its outbreak range (Andersson and Jonasson 1980; Bylund 1995), while in continental areas, the outbreaks are irregular or lacking (Tenow 1972, 1996; 
Tenow and Holmgren 1987; Ruohomäki et al. 1997). It is well known that the mortality of overwintering eggs of E. autumnata caused by winter minimum temperatures is the main factor determining the topographical distribution of damage in mountain birch forests; temperatures in the valleys are generally low enough to kill the eggs, while (due to temperature inversion) the upper slopes are warmer during cold winter periods and outbreaks may occur (Tenow 1972, 1975; Kallio and Lehtonen 1973; Niemelä 1979; Virtanen et al. 1998).

Topographical and year-to-year temperature variation provide an opportunity to test different hypotheses concerning the relationships between temperature and the risk of forest insect outbreaks. Niemelä (1980) proposed that the outbreaks of E. autumnata are associated with low summer temperatures. On the other hand, Ayres (1993) suggested that increased summer temperatures enhance the development of E. autumnata larvae more than that of their host trees, an increase of $1{ }^{\circ} \mathrm{C}$ potentially tripling the population growth rate of the herbivore. Finally, a generally warmer environment may also allow ants, parasitoids, and other natural enemies to kill a higher proportion of moth larvae and/or pupae (Laine and Niemelä 1980; Neuvonen et al. 1996, see also: Karhu and Neuvonen 1998; Tanhuanpää et al. 1999).

In this paper, we study topographical and year-toyear variation in the performance (pupal weights, survival) and parasitism of E. autumnata larvae. First, we test whether sites at altitudes ranging from $80 \mathrm{~m}$ to $320 \mathrm{~m}$ above sea level (a.s.l.) show differences, and whether these differences are consistent between years. Second, we test whether the variation in E. autumnata performance and parasitism can be explained by altitude and/or temperature variation among sites and years. We also compare the potential strength of the effects (food plant quality, parasitism) causing summer spatial variation in E. autumnata performance with that due to variation in minimum winter temperatures. Finally, we discuss how the predicted warmer summer climate may affect the population dynamics of E. autumnata.

\section{Material and methods}

Study area and sites

The study was conducted near the Kevo Subarctic Research Station $\left(69^{\circ} 45^{\prime} \mathrm{N}, 27^{\circ} \mathrm{E}\right)$ in northern Finland. Four study sites were used in 1993-1996 and six additional sites in 1995-1996 (Fig. 1, Table 1). At each site, eight different birches within a $50 \times 50 \mathrm{~m}$ area were selected as study trees each year. The birches were from 2 to $5 \mathrm{~m}$ high (mean $3.2 \mathrm{~m}$ ).

\section{E. autumnata and birches}

Larval performance was measured by enclosing 20 E. autumnata eggs (from 20 different broods; ready to hatch within some hours) into a mesh bag that was placed over the distal part of a branch (about $1.5 \mathrm{~m}$ height; one per birch). The experiments were started on different days at different study sites and years (an attempt was

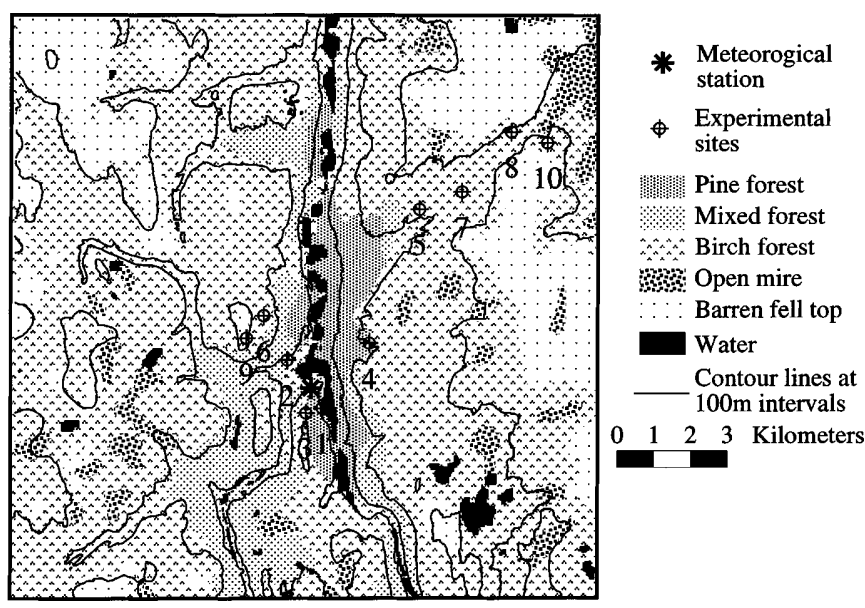

Fig. 1 Location of the Kevo Meterological Station, and our study sites. The major vegetation types in the area are based on the map of Seppälä and Rastas (1980). Criteria for vegetation type classes: Pine forest, at least $20 \%$ of the area covered by Scots pine; Mixed forest, mountain birch forest with scattered Scots pines, with less than $20 \%$ of the area covered by pines; Birch forest, some parts were damaged by Epirrita autumnata in the mid-sixties and are only partly recovered; Open mire, mire without forest cover; Barren fell top, area above the tree limit
Table 1 Description of the study sites: altitude above sea level, yearly temperature sums, mean of temperature during larval period in study years, and vegetation types (see criteria for the classifica- tions in the legend to Fig. 1). Sites 1, 3, 6 and 8 were used every year, others only in 1995 and 1996

\begin{tabular}{rlllll}
\hline Site & $\begin{array}{l}\text { Altitude above } \\
\text { sea level }(\mathrm{m})\end{array}$ & $\begin{array}{l}\text { Mean yearly } \\
\text { degree-days } \\
\text { over } 2^{\circ} \mathrm{C}\end{array}$ & $\begin{array}{l}\text { Mean yearly } \\
\text { degree-days } \\
\text { over } 5^{\circ} \mathrm{C}\end{array}$ & $\begin{array}{l}\text { Mean temperature } \\
\text { during larval period }\left({ }^{\circ} \mathrm{C}\right)\end{array}$ & Vegetation type \\
\hline 1 & 85 & 1031.6 & 640.0 & 10.20 & Mixed forest \\
2 & 100 & 988.3 & 619.0 & 10.46 & Mixed forest \\
3 & 190 & 992.4 & 615.0 & 10.27 & Birch forest \\
4 & 200 & 908.9 & 551.0 & 9.94 & Birch forest \\
5 & 215 & 922.1 & 557.6 & 10.27 & Birch forest (near old Epirrita damage) \\
6 & 230 & 938.2 & 570.2 & 10.04 & Birch forest \\
7 & 240 & 883.5 & 533.0 & 9.95 & Birch forest (near old Epirrita damage) \\
8 & 285 & 829.7 & 489.1 & 10.09 & Birch forest (near old Epirrita damage) \\
9 & 305 & 872.9 & 514.8 & 10.25 & Birch forest (near treeline) \\
10 & 310 & 791.1 & 441.9 & 9.65 & Birch forest (near treeline)
\end{tabular}


made to match the start of the experiment with average bud-burst of the birches at each site); all the bags at each site were set up on the same day. At the same time, the state of bud emergence was estimated for every birch (mean of 20 buds) by comparing the length of unfurled leaves to that of the bud scales (see Sulkinoja and Valanne 1987); the phenology scale varied from 1 (leaves still enclosed within buds) to 4 (leaf blades fully emerged) with an accuracy of 0.5 units.

During the early larval period, fine mesh bags $(0.4-\mathrm{mm}$ mesh, holes $0.2 \mathrm{~mm}$; length $30 \mathrm{~cm}$ ) were used to ensure that the young larvae could not escape from the bags. When the larvae were in their third instar, the mesh bags were changed to larger ones with a larger mesh size (1-mm mesh, holes $0.8 \mathrm{~mm}$; length $60 \mathrm{~cm})$. The smallest parasitoid of E. autumnata found in our study, Eulophus larvarum (L.), could pass through the larger mesh, while larger species could parasitize E. autumnata larvae at least by sticking their ovipositor through the bag. The larvae were left to feed in the bags until the end of their larval period, and the bags containing the larvae were transported to the laboratory when the larvae started to pupate. The larvae were allowed to pupate solitarily in $50-\mathrm{ml}$ plastic vials containing Sphagnum moss. The pupae were sexed and weighed after 2 weeks; emerged parasitoids were determined and counted.

\section{Temperature measurement and modelling}

Temperature was recorded (30-min intervals) at the study sites (1994-1995 at all sites, in 1996 at seven sites) with HamsterTM (Elpro, Buchs, Switzerland) dataloggers at a height of $1.5 \mathrm{~m}$ on one birch in the centre of each study area. The dataloggers were protected from direct sunlight. As we did not record temperature at any of the sites in 1993 nor at three sites in 1996, we developed regression models based on temperatures recorded at Kevo Meteorological Station (within the study area; Fig. 1) for estimating the missing data. Temperature recorded (eight times daily; every $3 \mathrm{~h}$ from 3.00 a.m. to 12.00 p.m. GMT) at the Meteorological Station $\left(T_{\text {stat }}\right)$ was used as the predictor variable. The site-specific temperatures at the respective times were estimated using the model: $T_{\mathrm{ij}}=a_{\mathrm{ij}}+b_{\mathrm{ij}} T_{\text {stat }}$. Separate parameters $\left(a_{\mathrm{ij}}\right.$ and $b_{\mathrm{ij}} ; \mathrm{i}=$ index of site, $\mathrm{j}=$ index of time) were estimated for each site and the daily measurement time because radiation conditions differ between the study sites and at different times of the day due to topography. We used all the available site-specific measurements from June to August for parameter estimation.

Daily mean temperatures and effective temperature sums were calculated for each site and year on the basis of measured (when available) or estimated eight daily temperatures. We calculated the effective temperature sums using both $+2^{\circ} \mathrm{C}$ and $+5^{\circ} \mathrm{C}$ as the threshold value (expressed as degree-days over $+2^{\circ} \mathrm{C}$ or $+5^{\circ} \mathrm{C}$, $\mathrm{dd} 2$ or dd5). Temperature sum calculations traditionally use $+5^{\circ} \mathrm{C}$ as the threshold (e.g. Sarvas 1972; Ayres and MacLean 1987; Sulkinoja and Valanne 1987; Ayres 1993), but a threshold of $+2^{\circ} \mathrm{C}$ gives the best fit when predicting the emergence of mountain birch leaves as a function of the temperature sum (our unpublished data; M. Kozlov, personal communication).

In 1994, we also studied the within-area temperature variation by placing digital thermometers on the study birches at a height of $1.5 \mathrm{~m}$. The thermometers recorded minimum and maximum temperatures. In addition to these measurements, the temperature values were recorded every time the thermometers were removed from the field. Measurements were made in the 24 birches within every area (study birches for the years 1993, 1994 and 1995) on 5 separate days with 2 -week intervals. The mean differences between the minimum, maximum and collection time temperatures and the area means were calculated for the each birch.

\section{Data treatment}

\section{We used the following response variables}

(1) Pupal weight (mg) of E. autumnata. To remove weight differences due to variable sex ratios, male weights were transformed to female weights before calculating the bag specific means using the following equation: female pupal weight $=-7.94+$ $1.16 \times$ male pupal weight (Kaitaniemi et al. 1999).

(2) Proportion of larvae found. As parasitism probabilities were high in the study years, survival without the effects of parasitism was calculated as the proportion (out of the number of enclosed eggs) of larvae found as full grown or parasitized at the end of the larval period. Thus, 1-(proportion of larvae found) estimates the mortality during the early larval period and that caused by factors other than parasitoids (e.g. birch foliage quality, weather). Proportion of larvae found also includes those full-grown larvae (about $1 \%$ ) which were found dead in the mesh bags: some of which were predated through the mesh bags by spiders or ants.

(3) Egg production index. An estimate of egg production per enclosing female assuming no mortality from parasitism. Pupal mass correlates strongly with the potential and realised fecundity of E. autumnata (Haukioja and Neuvonen 1985; Tammaru et al. 1996). We used the following equation: eggs female $=-101.9+2.93 \times$ female pupal weight $(\mathrm{mg})($ Tammaru et al. 1996). Thus, egg production index $=$ [proportion of larvae found $\times(-101.9+2.93 \times$ pupal weight $)] / 2$.

(4) The apparent parasitism probability was calculated as the proportion of parasitized larvae out of all larvae found.

(5) Apparent parasitism caused by different parasitoid species; E. larvarum (L.), Eulophidae; Cotesia jucunda (Marshall), Braconidae; Zele deceptor (Wesmael), Braconidae.

\section{Statistical analysis}

We analysed the data in two different steps. First, we made analyses based on the birch-specific values (when within-site variation could also be taken into account). In these analyses, the explanatory variables were site (class variable), year (class variable), and their interaction, bud state at the start of the experiment (continuous variable), and birch-specific local climate (differences in minimum, mean, and maximum temperatures from the site means). As some bags were destroyed by wind or other factors, the number of the observations in survival and parasitism analyses was 193. As we did not obtain pupal weight estimates for all the birches due to high parasitism and/or low survival, in pupal weight and egg production index analyses, the number of the observations was 139 .

In the second step, we made our analyses on the basis of sitespecific means. As the bud state at the start of the experiment significantly affected, in the birch-specific analysis, some of the response variables (Table 2, Fig. $2 \mathrm{a}-\mathrm{c}$ ), we removed bud state effects from the site-specific values by using the bud state as a covariate when calculating the site-specific values for pupal weight, survival and egg production index. The altitude of the site and the mean temperatures for the whole or different parts of the larval period (first 2 weeks, next 2 weeks, and last 2 weeks) were also used as continuous explanatory variables. In addition, the study year (class variable) was used as an explanatory variable. Due to the destruction of many bags we could not take sites 4 and 7 from the year 1995 into the analyses, so the number of observations in the analyses was 26. We performed all the ANOVAs using Proc GLM (SAS 1990). In the analysis shown in Table 2 we used type III sums of squares. In the analyses in Tables 3 and 4, we have presented type I sums of squares; this enabled us to take into account first the year-, then altitude-, and finally the temperature-related variation. However, even if we had used type III sums of squares in these analyses, the results would have been the same.

\section{Results}

Variation among sites and years

Total variation in the annual temperature sums at our study sites during the study years ranged from $695 \mathrm{dd} 5$ 
to $427 \mathrm{dd} 5$, which is comparable to roughly a $200-\mathrm{km}$ latitudinal shift in Finnish Lapland (see Ritari and Nivala 1993). Site-specific means of the temperature sums and mean temperatures are presented in Table 1. When the effective temperature sums (dd5) are compared to the mean temperature sum during the last 34 years (1963-1996), summer 1993 was the 6th, 1996 was the 8th, 1995 the 14th, and 1994 the 20th coldest at the Kevo meteorological station. The total variation in mean temperature during the larval period of $E$. autumnata was from $+9.0^{\circ} \mathrm{C}$ to $+11.3^{\circ} \mathrm{C}$ at our study sites. The temperature variation and timing of the larval period during our study are presented in Fig. 2a-d.

Pupal weight of E. autumnata showed little or no variation between the sites or years (Table 2); site means calculated over the study years ranged from $64.7 \mathrm{mg}$ to $76.2 \mathrm{mg}$, and yearly means only from $70.8 \mathrm{mg}$ in 1993 to $72.3 \mathrm{mg}$ in 1995 . There were differences between both sites and years in the proportion of larvae found and the egg production index (Table 2). The proportion of larvae found was $40 \%, 70 \%, 62 \%$, and $56 \%$ in 1993,1994 , 1995 and 1996, respectively. Yearly means in the egg production index ranged from 20.0 in 1993 to 37.7 in 1994. Site and year interactions were not found in the analyses of pupal weight, proportion of larvae found or egg production index (Table 2). The advanced phenology of the birches in relation to the start of the larval period reduced the pupal weight and egg production index (Fig. 3a-c, Table 2).

There were differences between the years in the total apparent parasitism probability: $36 \%, 62 \%, 63 \%$ and $35 \%$ in $1993,1994,1995$ and 1996 , respectively (Table 2). The apparent parasitism probabilities were also different between the sites in different years (Table 2): they were highest at most of the sites in 1994 and 1995, but in the two altitudinally highest sites, in 1996. The differences in the parasitism probabilities of the individual parasitoid species were greatest between the sites, although year effects and and site and year interactions were also found (Table 2). The relative abundances of the different parasitoids calculated over the whole study period and all the sites were as follows: $E$. larvarum $35 \%, Z$. deceptor $38 \%, C$. jucunda $27 \%$, and Campoletis varians (Thomson), Ichneumonidae $0.5 \%$. C. jucunda was not found in 1993 at all, and in 1994 its abundance was low compared to that of E. larvarum and $Z$. deceptor. The advanced phenology of the birches at the start of the larval period had no effect on the parasitism of E. autumnata (Table 2).

Responses associated with altitude and/or temperature variation among sites and years

The proportion of larvae found and the egg production index were low at the highest mean temperatures $\left(+11^{\circ} \mathrm{C}\right)$, but were relatively similar in the temperature range from +9 to $+10.5^{\circ} \mathrm{C}$ (mean temperature of the larval period; Fig. 4b, c, Table 3). When the effect of temperature was studied in the analysis as a separate variable for different parts of the larval period, the direction of the effect was the same as in the mean temperature analysis. Temperature had not significant effect on pupal weights (Fig. 4a, Table 3). Pupal weight, proportion of larvae found and egg production index were not related to the altitude of the sites (Table 3 ).
Fig. 2a-d Weekly mean temperatures during our study summers at the Kevo Meteorological Station. Error bars show standard deviations of daily values. Squares show the starting and the ending times of the larval periods at the earliest and latest study site
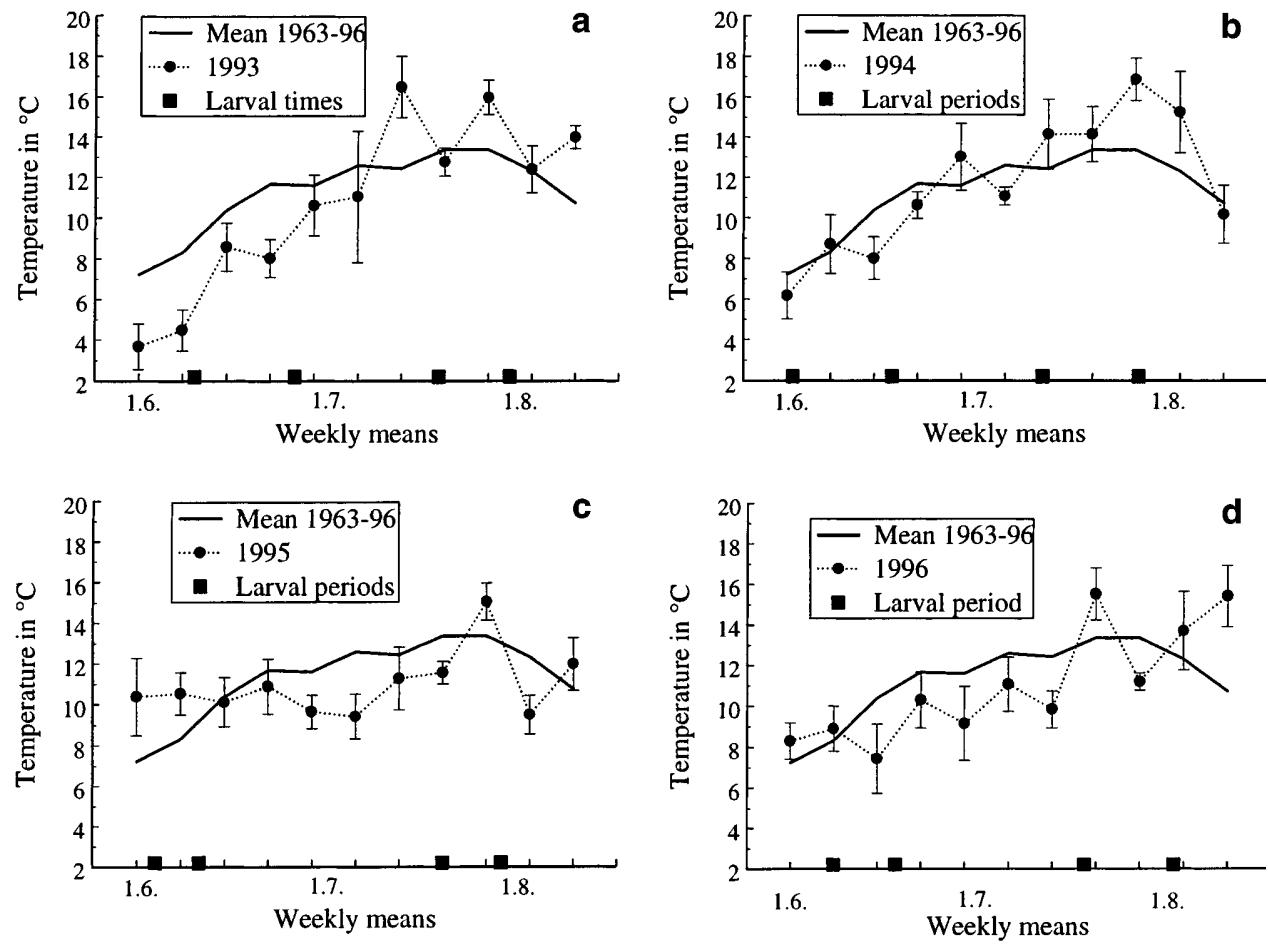
Table 2 ANOVA tables for the birch-specific values. Type III sums of squares are used. See definition of the variables in Materials and methods (EMS error mean square)

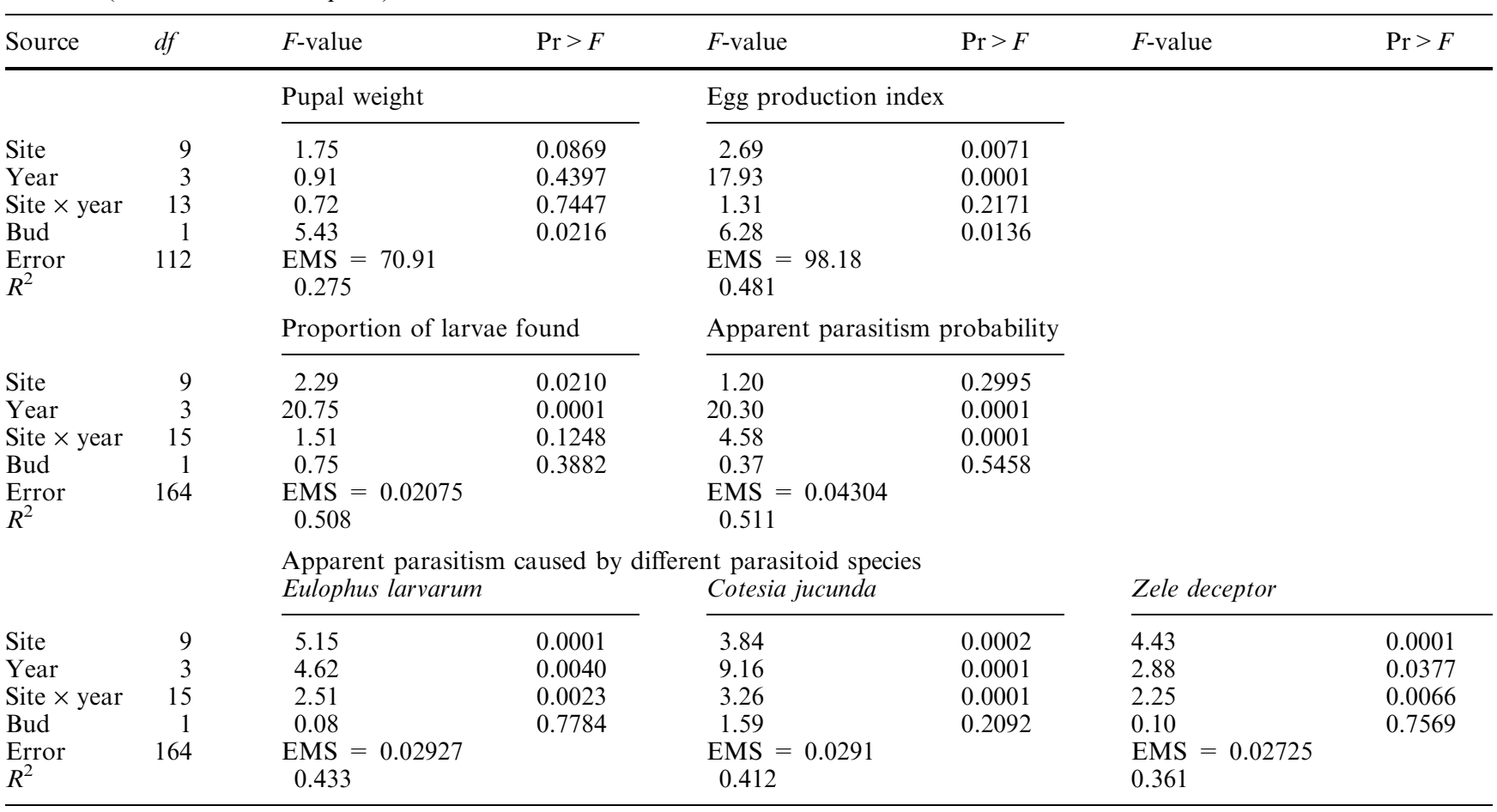

A high temperature during the last 2 larval weeks was related to a high apparent parasitism probability in three of the four study years (1993, 1995, 1996; Fig. 5, Table 4). As expected, only the temperatures during the last 2 larval weeks affected the parasitism rates (although not in the case of $Z$. deceptor), since parasitism was excluded during the first part of the larval period by the dense mesh bags.

There were no clear differences in the apparent parasitism probability relative to site altitude when the parasitism caused by all the parasitoid species was summed (Table 4). However, when the parasitoid species were analysed separately, E. larvarum was most abundant at sites with a low altitude, $C$. jucunda at high altitudes, and $Z$. deceptor occurred especially at medium altitudes (Fig. 6a-c, Table 4).

\section{Within-area temperature variation}

The birch-specific absolute mean values of difference in temperatures within areas were: for minimum temperatures $0.15^{\circ} \mathrm{C}$ (range $0-0.48$, SD 0.11 ), for maximums $0.40^{\circ} \mathrm{C}(0-0.52$, SD 0.33$)$, and for collection time temperatures $0.20^{\circ} \mathrm{C}(0-0.70, \mathrm{SD} 0.17)$. The lowest minimum temperatures occurred at the topographically low sites in the area. The variation in the maximum temperatures was probably due to the different solar radiation conditions, despite the fact that the thermometers were shielded from direct sunlight. This slight within-site temperature variation had no statistically significant effect on the performance or parasitism of E. autumnata (all $P$-values $>0.08$ ).

\section{Discussion}

Local climate and birch quality for E. autumnata

The altitude of the sites (ranging from $80 \mathrm{~m}$ to $320 \mathrm{~m}$ a.s.l.) had no consistent effect on the pupal weights of E. autumnata, neither was the variation in this variable explained by the temperature during the larval period (range from +9 to $+11.3^{\circ} \mathrm{C}$ ). However, another parameter was probably associated with host quality and direct climatic effects: the proportion of larvae found was lowest at the highest temperatures although there was no clear trend in the temperature range from +9 to $+10.5^{\circ} \mathrm{C}$.

The egg production index, which combines the variation in pupal weight and proportion of larvae found, was about $50 \%$ lower at a temperature of $+11^{\circ} \mathrm{C}$ compared to $+9^{\circ} \mathrm{C}$. Ayres (1993) suggested that an increase in average temperature of only $1^{\circ} \mathrm{C}$ can triple the potential growth rate (=egg production index; M.P. Ayres, pers. comm.) of E. autumnata. His result was based on a small manipulative experiment with greenhouses built around the study trees versus controls during two summers, and hence his conclusion was based on only four data points. Although the temperatures in his study varied from $+10.5^{\circ} \mathrm{C}$ to $+13.7^{\circ} \mathrm{C}$ (i.e. exceeding the highest temperatures in our study), the egg production indexes in his experiment (M.P. Ayres, personal communication) were within the range of our observations at $+11^{\circ} \mathrm{C}$, and clearly lower than ours at $+9^{\circ} \mathrm{C}$. In conclusion, our results do not support the hypothesis of Ayres (1993) that elevated temperatures 

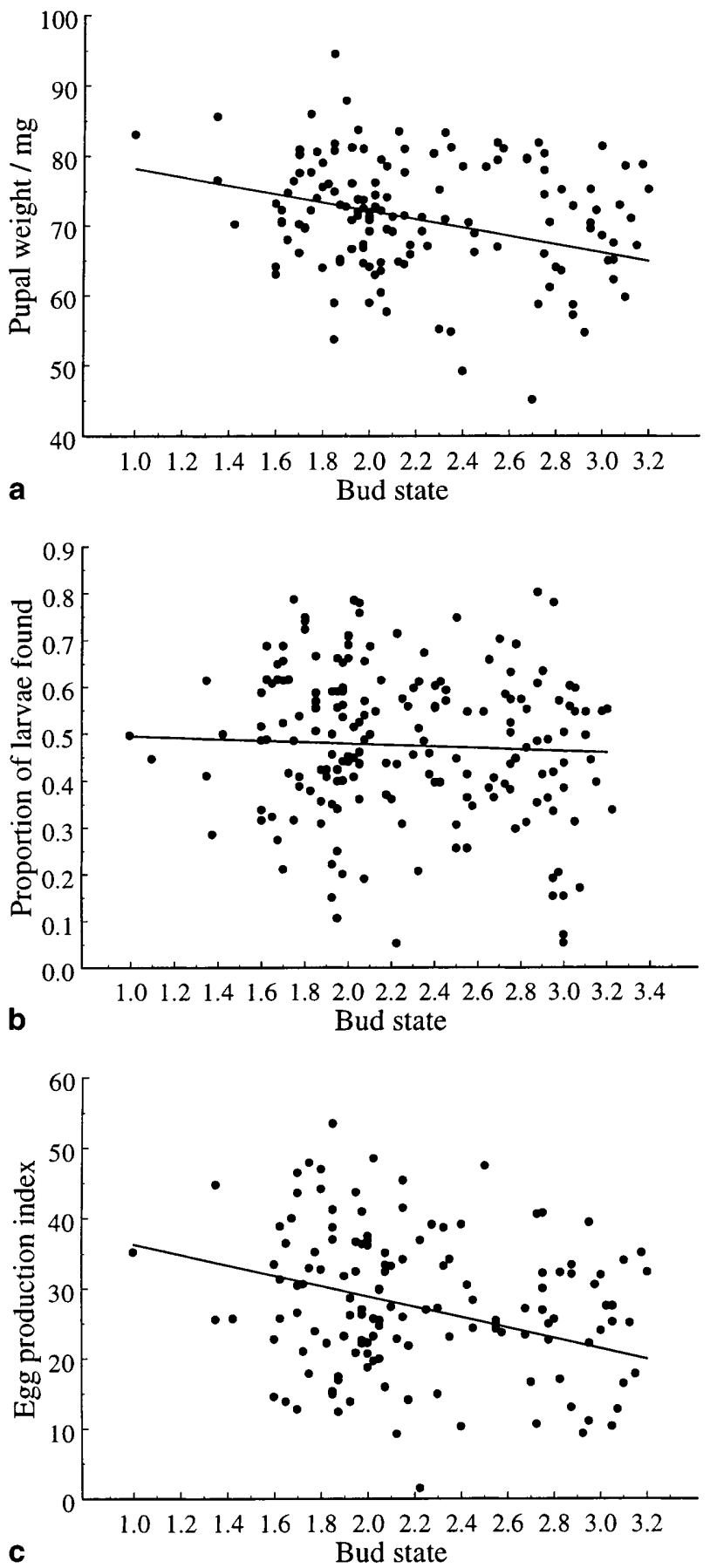

Fig. 3 Association between bud state at the start of the experiment and pupal weight (pupal weight $=83.77-5.69 \times$ bud state) (a), survival (b) and egg production index (egg production index = 36.35-7.20 $\times$ bud state) (c) of E. autumnata. Values of the response variables are corrected values taking into account the effects of the study site and study year

can favour E. autumnata by allowing the larvae to complete their development before the leaves do.

There was some variation in host foliage quality among the sites (Table 2) which could not be explained by altitude. There is also large variation in the foliage quality of mountain birches among the individual trees
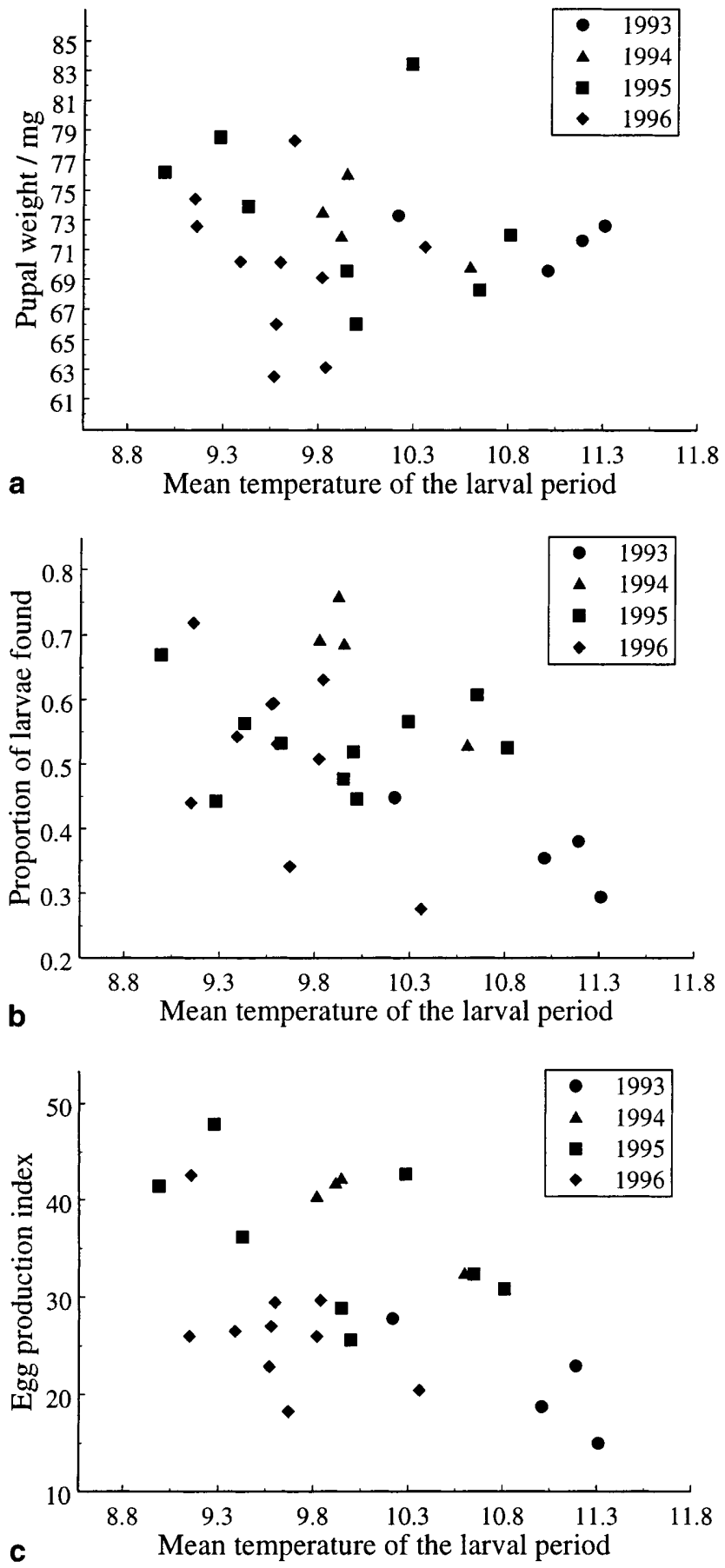

Fig. 4 Association between the mean temperature during the larval period and pupal weight (a), survival (b) and egg production index (c) of E. autumnata

within a site (Suomela and Ayres 1994; Suomela and Nilson 1994; Suomela et al. 1995). This variation in birch quality can be due to many different factors: the genotype of the trees (Hanhimäki et al. 1994), or local nutrient/moisture conditions which can in turn lead to changes in plant chemistry, and in the performance of E. autumnata (Haukioja et al. 1985; Ayres and MacLean 1987; Suomela and Ayres 1994; Suomela et al. 1995). 
Table 3 ANOVA table of the performance indexes of E. autumnata for site-specific values. Type I sums of squares are used (Meantemp mean temperature of the larval period; $E M S$ error mean square)

\begin{tabular}{|c|c|c|c|c|c|c|c|}
\hline \multirow[t]{2}{*}{ Source } & \multirow[t]{2}{*}{$d f$} & \multicolumn{2}{|l|}{ Pupal weight } & \multicolumn{2}{|c|}{ Proportion of larvae found } & \multicolumn{2}{|c|}{ Egg production index } \\
\hline & & $F$-value & $\operatorname{Pr}>F$ & $F$-value & $\operatorname{Pr}>F$ & $F$-value & $\operatorname{Pr}>F$ \\
\hline Year & 1 & 1.05 & 0.3915 & 8.47 & 0.0008 & 10.17 & 0.0003 \\
\hline Altitude & 3 & 0.62 & 0.4413 & 0.45 & 0.5084 & 0.58 & 0.4570 \\
\hline Meantemp & 1 & 1.42 & 0.2479 & 5.44 & 0.0302 & 11.16 & 0.0033 \\
\hline Error & 20 & $\mathrm{EMS}=21.612$ & & $\mathrm{EMS}=0.00838$ & & $\mathrm{EMS}=30.857$ & \\
\hline$R^{2}$ & & 0.206 & & 0.610 & & 0.686 & \\
\hline
\end{tabular}

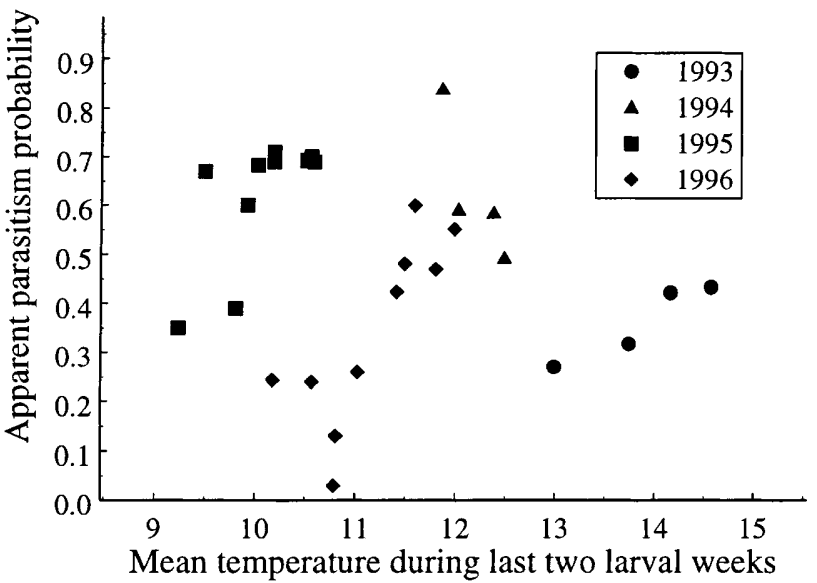

Fig. 5 Association between mean temperature during the last 2 weeks of the larval period and the apparent parasitism probability of E. autumnata

Senn et al. (1992) suggested that the mountain birch leaves produced in a year following a summer with a low temperature sum are of low quality for herbivorous insects. However, we did not found any clear trend between the previous-year temperature sum and $E$. autumnata performance.

One important additional question relating to mountain birch quality is the defoliation-induced responses in leaf quality. They seem to be at least partly behind the cycles of E. autumnata (Haukioja et al. 1988; Bylund 1995; Kaitaniemi et al. 1999). Haukioja et al.

Table 4 ANOVA table of apparent parasitism probabilities calculated according to the site-specific means. Type I sum of squares are used. (Starttemp mean temperature of the 2 first larval weeks,
(1983) suggested that delayed induced responses are weak after cold summers due to resource shortage of the birches. However, the correlations between the efficacy of inducible responses and the temperature sums of the defoliation and the following larval rearing year were non-significant in a larger data set (Ruohomäki et al. 1992).

Natural enemies of E. autumnata and their relation to temperature conditions

We found a positive correlation between high temperature during the last 2 larval weeks and the apparent parasitism probability. During cold periods, the activity of ectotherm parasitoids or predators may be suppressed when their herbivorous hosts or prey are still capable of feeding (Stamp 1993). Furthermore, parasitism and predation rates are known to increase more than the developmental rate of host or prey herbivores when the temperature increases (Kingsolver 1989). The temperatures in our study area are generally so low that parasitoid flying activity mainly occurs only during the warmest days (Nuorteva and Jussila 1967). Thus, the connection between high temperature and parasitism rate was probably due to the higher parasitoid activity on warmer days.

The use of fine mesh bags in the beginning of the larval period to prevent small E. autumnata larvae from escaping also prevented the attack of the phenologically earliest parasitoids. Two early season flying parasitoids

Midtemp mean temperature of the next 2 larval weeks, Endtemp mean temperature of the 2 last larval weeks, EMS error mean square)

\begin{tabular}{|c|c|c|c|c|c|c|c|c|c|}
\hline \multirow[t]{3}{*}{ Source } & \multirow[t]{3}{*}{$d f$} & & & \multicolumn{6}{|c|}{ Apparent parasitism caused by different parasitoid species } \\
\hline & & \multicolumn{2}{|c|}{ Apparent parasitism probability } & \multicolumn{2}{|l|}{ E. larvavum } & \multicolumn{2}{|l|}{ C. jucunda } & \multicolumn{2}{|l|}{ Z. deceptor } \\
\hline & & $F$-value & $\operatorname{Pr}>F$ & $F$-value & $\operatorname{Pr}>F$ & $F$-value & $\operatorname{Pr}>F$ & $F$-value & $\operatorname{Pr}>F$ \\
\hline Year & 3 & 16.77 & 0.0001 & 4.89 & 0.0104 & 3.92 & 0.0237 & 2.18 & 0.1225 \\
\hline Altitude & 1 & 1.03 & 0.3234 & 16.23 & 0.0007 & 7.95 & 0.0106 & 2.58 & 0.1242 \\
\hline Starttemp & 1 & 1.92 & 0.1815 & 0.57 & 0.4588 & 0.00 & 0.9801 & 0.45 & 0.5082 \\
\hline Midtemp & 1 & 1.98 & 0.1751 & 0.03 & 0.8544 & 0.01 & 0.9390 & 2.13 & 0.1596 \\
\hline Endtemp & 1 & 29.95 & 0.0001 & 6.66 & 0.0178 & 8.44 & 0.0087 & 0.00 & 0.9961 \\
\hline $\begin{array}{l}\text { Error } \\
R^{2}\end{array}$ & 20 & $\begin{array}{c}\mathrm{EMS} \\
0.810\end{array}$ & & $\begin{array}{l}\mathrm{EMS}=0.00860 \\
0.656\end{array}$ & & $\begin{array}{l}\mathrm{EMS}=0.01181 \\
0.585\end{array}$ & & $\begin{array}{l}\text { EMS }=0.01250 \\
0.396\end{array}$ & \\
\hline
\end{tabular}




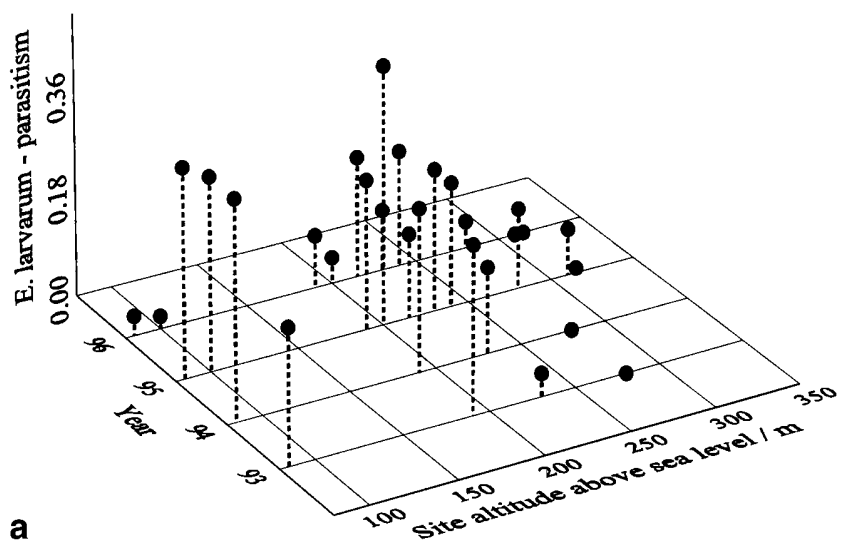

benefited from our exclusion of the earlier (and bigger) parasitoid species by the fine mesh bags during the first part of the larval period. In our study, C. jucunda was relatively the most abundant at high altitudes, and E. larvarum, the smallest of our parasitoid species, the most abundant at low altitudes. Correspondingly, Jussila (1968) found in the Kevo area that big and strongly built Ichneumonidae species preferentially inhabited the areas at higher elevations, while the smallest ones were mainly found at the lowest sites. He explained this on the basis of local wind and humidity conditions.

Parasitoids can generally produce cycles in the population dynamics of their host if the parasitoids are so highly specialized that their populations collapse with declining host density (see Myers 1988). Many of the parasitoids of E. autumnata are forced to near specialism due to the lack of alternative hosts in subarctic areas (Haukioja et al. 1985; Ruohomäki 1994). After an E. autumnata outbreak, the populations of parasitoids are known to collapse and probably even become locally extinct during the low phase of the E. autumnata cycle (Nuorteva 1971; Ruohomäki 1994; Bylund 1995). Predators of E. autumnata, which are generalistic, cannot create cyclic population dynamics (Haukioja et al. 1988). However, they can prevent outbreaks at least locally (e.g. Laine and Niemelä 1980; Karhu and Neuvonen 1998). Predation and/or parasitism by generalist parasitoids are also suggested to be the reasons for the lack of outbreaks in the southern parts of the distribution area of E. autumnata (Haukioja et al. 1983, 1988; Tanhuanpää et al. 1999).

The role of parasitoids and predators in the population dynamics of E. autumnata may change in the future if the predicted climate warming occurs (see Houghton et al. 1996). The attack activity of parasitoids, as well as that of ectotherm generalist predators (spiders and ants), can increase at higher temperatures. Pupal predation (caused mainly by small mammals) cannot regulate E. autumnata populations in the present climate in the outbreak area (Neuvonen 1988; Tanhuanpää et al. 1999). As the length of the pupal period is likely to increase if the climate warms (see Haukioja et al. 1988; Tammaru et al. 1999), the time when they are exposed to pupal predators, and thus also the significance of pupal predation, will probably increase.

Fig. 6 Association between study site altitude and the parasitism rate of different parasitoid species: Eulphus larvarum (a), Cotesia jucunda (b), and Zele deceptor (c)

found by Kaitaniemi and Ruohomäki (1999) in 1995 near our study area were not observed in our study: Aleiodes testaceus (Spinola) [= gastritor (Thunberg)], Braconidae, and Phobocampe neglecta (Holmgren), Ichneumonidae. $C$. jucunda and $Z$. deceptor were abundant species in both of these studies, and both have a long flight period in the area (Kaitaniemi and Ruohomäki 1999). E. larvarum was relatively more abundant than the other species in our data than in the data of Kaitaniemi and Ruohomäki (1999); thus, it may have

Variation in E. autumnata performance due to winter and summer temperatures

Our results suggests that warmer summers may have opposite consequences for E. autumnata populations than warmer winters (cf. Virtanen et al. 1998). The potential strength of the effects due to summertime temperature variation on E. autumnata densities seems to be clearly less than that due to the variation in minimum winter temperatures (Table 5). Thus, when trying to explain the spatially explicit E. autumnata densities in the present climate in our study area, the most important 
Table 5 Comparison of the coefficients of variation between different performance parameters of E. autumnata. Data of pupal weights, proportions of larvae found, egg production indexes and apparent parasitism probabilities are from this study. Egg winter mortality data are the field observations from the study of Virtanen et al. (1998). Egg mortality sites are classified according to altitude above sea level at 50-m intervals, corresponding to those in Tables 1 and 5 in Virtanen et al. (1998)

\begin{tabular}{llll}
\hline $\begin{array}{l}\text { Coefficient of variation } \\
\text { in relation to index in summer }\end{array}$ & $\begin{array}{l}\text { Sites } \\
(\%)\end{array}$ & $\begin{array}{l}\text { Years } \\
(\%)\end{array}$ & $\begin{array}{l}\text { Overall } \\
\text { mean }(\%)\end{array}$ \\
\hline $\begin{array}{l}\text { Egg mortality in winter } \\
\text { Apparent parasitism probability }\end{array}$ & 62.6 & 64.5 & 85.6 \\
$\quad$ in summer & 21.5 & 14.6 & 39.0 \\
$\begin{array}{l}\text { Proportion of larvae } \\
\quad \text { found in summer }\end{array}$ & & 23.0 \\
$\begin{array}{l}\text { Pupal weight in summer } \\
\text { Egg production index }\end{array}$ & 4.7 & 5.2 & 6.5 \\
\hline
\end{tabular}

factor seems to be the spatial distribution of egg mortality during winter. Correspondingly, Bylund (1995) did not found correlation between the mean air temperatures during the larval period and the density of $E$. autumnata larvae during the same year, nor the population growth rate calculated between year $t$ and $t-1$. In contrast, she found a positive correlation between minimum air temperatures in mid-winter and the population growth rate.

During summer, the variation in E. autumnata performance caused by parasitoids seems to be greater than that caused by differences in the quality of mountain birch (Table 5). However, between-site variation in parasitism probabilities is mainly due to different parasitism probabilities between the sites in different study years (see Table 2). The variation in pupal weights is only one-third to one-fourth of that in the proportion of larvae found (Table 5). However, the importance of different sources of the variation during summer certainly varies within the cycle (see Bylund 1995).

\section{Conclusion}

The potential frequency and area of E. autumnata outbreaks in the continental parts of Fennoscandia will become larger than at present if winter temperatures increase as predicted (Tenow 1996; Virtanen et al. 1998). However, the predicted changes in summer temperature may have effects in another direction. In a warmer summer climate, the intensity of outbreaks may decrease due to increased parasitoid and predator activity, and cyclicity might even totally disappear. Furthermore, it is probable that the better recovery ability of the birches after warmer summers (see Kallio and Lehtonen 1973; Haukioja et al. 1985) will decrease the severity of $E$. autumnata damage in predicted warmer summers. Our results also support and explain the earlier observation that $E$. autumnata outbreaks are associated with cool summers, and that the range of E. autumnata damage has remained relatively small during warm summers during the known outbreaks in the 20th century in Fennoscandia (Niemelä 1980). In conclusion, our study indicates that if summers warm up as predicted, the intensity of $E$. autumnata outbreaks in the future will probably decrease.

Acknowledgements We would like to thank Pekka Kaitaniemi, Kyösti Lempa, Kai Ruohomäki, Miia Tanhuanpää and two anonymous referees for their constructive comments. We are grateful to Matt Ayres, Pekka Kaitaniemi, and Kai Ruohomäki for providing access to their data. We also thank all the Kevo staff and the field assistants: especially Liinu Törvi who helped during all the study years, and Antti Kause, Kirsi Loponen, Virpi Lummaa, Katja Mikalahti, and everyone else who lent a helping hand during the work. John Derome kindly checked our English. This study was financed by the Academy of Finland (SILMU, The Finnish Research Programme on Climate Change), The Maj and Tor Nessling Foundation, and The Emil Aaltonen Foundation.

\section{References}

Andersson G, Jonasson JA (1980) Relative abundance of insects on mountain birch at Ammarnäs, Swedish Lapland (in Swedish with English summary). Entomol Tidskr 101:61-69

Ayres MP (1993) Plant defense, herbivory, and climate change. In: Kareiva PM, Kingsolver JG, Huey RB (eds) Biotic interactions and global change. Sinauer, Sunderland, Mass, pp 75-94

Ayres MP, MacLean SF Jr (1987) Development of birch leaves and the growth energetics of Epirrita autumnata (Geometridae). Ecology 68:558-568

Berryman AA (1996) What causes population cycles of forest Lepidoptera? Trends Ecol Evol 11:28-32

Berryman AA, Stenseth NC, Isaev AS (1987) Natural regulation of herbivorous forest insect populations. Oecologia 71:174-184

Broekhuizen N, Evans FH, Hassell MP (1993) Site characteristics and the population dynamics of the pine looper moth. J Anim Ecol 62:511-518

Bylund $\mathrm{H}$ (1995) Long term interactions between the autumnal moth and mountain birch: the roles of resources, competitors, natural enemies, and weather. PhD thesis, Swedish University of Agricultural Sciences, Uppsala

Hanhimäki S, Senn J, Haukioja E (1994) Performance of insect herbivores on hybridising trees: the case of subarctic birches. J Anim Ecol 63:163-175

Haukioja E, Neuvonen S (1985) The relationship between size and reproductive potential in male and female Epirrita autumnata (Lep., Geometridae). Ecol Entomol 10:267-270

Haukioja E, Niemelä P, Kapiainen K (1983) Herbivory and treeline birches. In: P Morisset, S Payette (eds) Tree line ecology. Proceedings of the Northern Quebec treeline conference, $\mathrm{Ku}$ ujjuarapik, 22 June-1 July 1981. Nordicana 47:153-158

Haukioja E, Niemelä P, Sirén S (1985) Foliage phenols and nitrogen in relation to growth, insect damage, and ability to recover after defoliation, in the mountain birch Betula pubescens ssp tortuosa. Oecologia 65:214-222

Haukioja E, Neuvonen S, Hanhimäki S, Niemelä P (1988) The autumnal moth in Fennoscandia. In: Berryman AA (ed) Dynamics of forest insect populations: patterns, causes, and implications. Plenum, New York, pp 163-178

Houghton JT, Meira Filho LG, Callander BA, Harris N, Kattenberg N, Maskell K (eds) (1996) Climate change 1995: the science of climate change. Cambridge University Press, Cambridge, UK

Hunter MD (1997) Incorporating variation in plant chemistry into a spatially explicit ecology of phytopahogous insects. In: Watt AD, Stork NE, Hunter MD (eds) Forests and insects. Chapman \& Hall, London, pp 81-96

Jussila R (1968) Distribution of Ichneumonidae (Hymenoptera) at different altitude belts in Finnish Lapland. Rep Kevo Subarctic Res Stat 4:84-94 
Kaitaniemi P, Ruohomäki K (1999) Effects of autumn temperature and oviposition date on timing of larval development and risk of parasitism in a spring folivore. Oikos 84:435-442

Kaitaniemi P, Ruohomäki K, Tammaru T, Haukioja E (1999) Induced resistance of host tree foliage during and after a natural insect outbreak. J Anim Ecol 68:382-389

Kallio P, Lehtonen J (1973) Birch forest damage caused by Oporinia autumnata (Bkh.) in 1965-66 in Utsjoki, N. Finland. Rep Kevo Subarctic Res Stat 10:55-69

Karhu KJ, Neuvonen S (1998) Wood ants and a geometrid defoliator of birch: predation outweighs beneficial effects through the host plant. Oecologia 113:509-516

Kingsolver JG (1989) Weather and the population dynamics of insects: integrating physiological and population ecology. Physiol Zool 62:314-334

Laine KJ, Niemelä P (1980) The influence of ants on the survival of mountain birches during an Oporinia autumnata (Lep., Geometridae) outbreak. Oecologia 47:39-42

Larsson S, Tenow O (1984) Areal distribution of a Neodiprion sertifer (Hym., Diprionidae) outbreak on Scots pine as related to stand condition. Holarctic Ecol 7:81-90

Lawton J (1994) Something new under the sun? Oikos 69:177-178

Martinat PJ (1987) The role of climatic variation and weather in forest insect outbreaks. In: Barbosa P, Schultz JC (eds) Insect outbreaks. Academic Press, New York, pp 241-268

Myers JH (1988) Can a general hypothesis explain population cycles of forest Lepidoptera? Adv Ecol Res 18:180-242

Myers JH (1998) Synchrony in outbreaks of forest Lepidoptera: a possible example of the Moran effect. Ecology 79:1111-1117

Neuvonen S (1988) Interactions between geometrid and microtine cycles in northern Fennoscandia. Oikos 53:393-397

Neuvonen S, Virtanen T, Nikula A, Varama M (1996) Climate change and the risks of forest insect outbreaks. In: Roos J (ed) The Finnish research programme on climate change: final report. Publications of the Academy of Finland 4/96. Edita, Helsinki, pp 275-280

Niemelä P (1979) Topographical delimitation of Oporinia-damages: experimental evidence of the effect of winter temperature. Rep Kevo Subarctic Res Stat 15:33-36

Niemelä P (1980) Dependence of Oporinia autumnata (Lep., Geometridae) outbreaks on summer temperature. Rep Kevo Subarctic Res Stat 16:27-30

Nuorteva P (1971) Decline of the parasite population of the geometrid moth Oporinia autumnata (Bkh.) during the second year after a calamity on birches. Ann Entomol Fenn 37:96

Nuorteva P, Jussila R (1967) Seasonal and zonal distribution of Ichneumonidae (Hym.) on a subarctic fell during a calamity of the geometrid moth Oporinia autumnata (Bkh.) on birches. Ann Entomol Fenn 33:155-164

Ritari A, Nivala V (1993) Numerical climate model for northern Finland in mesoscale. In: Nikula A, Ritari A, Lahti M-L (eds) The use of spatial data and satellite image information in forest research (in Finnish). Research paper 479, Finnish Forest Research Insititute, pp 88-98

Ruohomäki K (1994) Larval parasitism in outbreaking and nonoutbreaking populations of Epirrita autumnata (Lepidoptera, Geometridae). Entomol Fenn 5:27-34

Ruohomäki K, Hanhimäki S, Haukioja E, Iso-Iivari L, Neuvonen S, Niemelä P, Suomela J (1992) Variability in the efficacy of delayed inducible resistance in mountain birch. Entomol Exp Appl 62:107-115

Ruohomäki K, Virtanen T, Kaitaniemi P, Tammaru T (1997) Old mountain birches at high altitudes are prone to outbreaks of
Epirrita autumnata (Lepidoptera: Geometridae). Environ Entomol 26:1096-1104

Sarvas R (1972) Investigations on the annual cycle of development of forest trees: active period. Commun Inst For Fenn 76:1-110

SAS (1990) SAS/STAT user's guide, version 6, 4th edn. SAS Institute, Cary, NC

Senn J, Hanhimäki S, Haukioja E (1992) Among-tree variation in leaf phenology and morphology and its correlation with insect performance in the mountain birch. Oikos 63:215-222

Seppälä M, Rastas J (1980) Vegetation map of the northernmost Finland with the special reference to subarctic forest limits and natural hazards. Fennia 158:41-61

Stamp NE (1993) A temperate region view of the interaction of temperature, food quality, and predators on caterpillar foraging. In: Stamp NE, Casey TM (eds) Caterpillars: ecological and evolutionary constraints on foraging. Chapman \& Hall, New York, pp 478-508

Sulkinoja M, Valanne T (1987) Leafing and bud size in Betula provenances of different latitudes and altitudes. Rep Kevo Subarctic Res Stat 20:27-33

Suomela J, Ayres MP (1994) Within-tree and among-tree variation in leaf characteristics of mountain birch and its implications for herbivory. Oikos 70:212-222

Suomela J, Nilson A (1994) Within-tree and among-tree variation in growth of Epirrita autumnata on mountain birch leaves. Ecol Entomol 19:45-56

Suomela J, Ossipov V, Haukioja E (1995) Variation among and within mountain birch trees in foliage phenols, carbohydrates, and amino acids, and in growth of Epirrita autumnata larvae. J Chem Ecol 21:1421-1446

Tammaru T, Kaitaniemi P, Ruohomäki K (1996) Realized fecundity in Epirrita autumnata (Lepidoptera: Geometridae): relation to body size and consequences to population dynamics. Oikos $77: 407-416$

Tammaru T, Ruohomäki K, Saloniemi I (1999) Within-season variability of pupal period in the autumnal moth a bet-hedging strategy. Ecology (in press)

Tanhuanpää M, Ruohomäki K, Kaitaniemi P, Klemola T (1999) Different impact of pupal predation on populations of Epirrita autumnata (Lepidoptera: Geometridae) within and outside the outbreak range. J Anim Ecol 68:562-570

Tenow O (1972) The outbreaks of Oporinia autumnata Bkh. and Operophthera spp. (Lep., Geometridae) in the Scandinavian mountain chain and northern Finland 1862-1968. PhD thesis, Zoologiska Bidrag från Uppsala, Uppsala University

Tenow O (1975) Topographical dependence of an outbreak of Oporinia autumnata Bkh. (Lep., Geometridae) in a mountain birch forest in Northern Sweden. Zoon 3:85-110

Tenow O (1996) Hazards to a mountain birch forest - Abisko in perspective. Ecol Bull 45:104-114

Tenow O, Holmgren B (1987) Low winter temperatures and an outbreak of Epirrita autumnata along a valley of Finnmarksvidda, the "cold pole" of Northern Fennoscandia. In: Alexandersson H, Holmgren B (eds) Climatological extremes in the mountains: physical background, geomorphological and ecological consequences. Uppsala Universitets Naturgeografiska Institution, UNGI report number 65, Uppsala, pp 203 216

Virtanen T, Neuvonen S, Nikula A (1998) Modelling topoclimatic patterns of egg mortality of Epirrita autumnata (Lepidoptera: Geometridae) with a Geographical Information System: predictions for current climate and warmer climate scenarios. J Appl Ecol 35:311-322 